\title{
O bordado Kalocsai: entre significados e ressignificações
}

\author{
Kalocsai embroidery: between meanings and resignifications
}

\section{Karolina Cabral Kosa ${ }^{\dagger *}$, Débora Pires Teixeira ${ }^{\ddagger}$ Carolina Morgado Pereira ${ }^{\S}$}

Como citar esse artigo. KOSA, K.C.; TEIXEIRA, D.P.; PEREIRA, C.M. O bordado Kalocsai: entre significados e ressignificações. Revista Mosaico, v.11, n.1, p. 10-17, 2020.

\author{
Resumo
}

Na presente pesquisa analisa-se a utilização do bordado Kalocsai, símbolo cultural húngaro, em um artigo do vestuário produzido em território brasileiro. Para tanto, foi utilizado como objeto de estudo uma toalha de mesa bordada à mão por uma imigrante húngara, confeccionada no Rio de Janeiro, em 1972, que foi analisada em seus aspectos têxteis, técnicos e simbólicos. Conclui-se, a partir da peça avaliada, que o exemplar do bordado Kalocsai, realizado no Brasil, apresentou aspectos têxteis e técnicos semelhantes aos produzidos no país de origem, no entanto, há presença do processo de ressignificação, a fim de perpetuar a cultura húngara, funcionando como um elo simbólico entre imigrantes e seu país de origem.

Palavras-chave: Bordado. Kalocsai. Hungria.

\begin{abstract}
This research analyzes the use of Kalocsai embroidery, a Hungarian cultural symbol, in an article of clothing produced in Brazilian territory. For this purpose, a table cloth hand embroidered by the Hungarian immigrant, made in Rio de Janeiro, in 1972, was used as the object of study, which was analyzed in its textile, technical and symbolic aspects. It is concluded, from the piece evaluated, that the Kalocsai embroidery example, made in Brazil, presented textile and technical aspects similar to those produced in the country of origin, however, there is the presence of the reframing process, in order to perpetuate the culture Hungarian, acting as a symbolic link between immigrants and their country of origin.
\end{abstract}

Keywords: Kalocsai. Embroidery. Hungary.

\section{Introdução}

Historicamente, a técnica do bordado se desenvolveu como um fazer feminino e doméstico, o que faz com que sua prática materialize questões sociais de gênero. Por séculos e por gerações, mulheres desenvolveram as habilidades de costurar, cerzir e bordar dentro do lar, espaço de invisibilidade econômica e social. Tais fazeres foram resignados à categoria de "artes menores" (SOUSA, 2019).

Desde o século XVI, as academias de arte passaram a congregar a formação e a consagração dos artistas. Tal sistema estabelecia a "hierarquia dos gêneros", classificando como "baixas" as artes aplicadas, vistas como domésticas e, por extensão, femininas. As artes têxteis, mesmo em inícios do século XX, ainda encontravam-se indissociavelmente ligadas a essa noção. Já nas primeiras décadas do século XX, alguns artistas se notabilizaram atuando nos domínios têxteis e tentando fazer deles gêneros autônomos. Um terceiro momento na relação entre artes, têxteis - sobretudo bordados - e a questão do gênero ocorreu com o advento do feminismo, nos anos 1970, no qual foi articulada uma revalorização das tradições "femininas" a um discurso político denunciador das práticas de discriminação de gênero (SIMIONI, 2010).

Conceitualmente, os bordados abrangem todos os trabalhos decorativos exercidos por meio de uma agulha sobre qualquer tipo de suporte pré - existente, como por exemplo, o tecido (SILVA, 2006). Conforme Sousa (2019), o bordado pode incluir pedrarias, paetês e contas diversas a fim de criar texturas e relevos em uma ilimitada possibilidade de experimentação. As configurações materiais do bordado "excedem a dimensão funcional e nos falam de concepções de

Afiliação dos autores:

† Licenciada em Belas Artes pela Universidade Federal Rural do Rio de Janeiro.

\$ Doutora em Economia Doméstica pela Universidade Federal de Viçosa, Professora Adjunta do Departamento de Economia Doméstica e Hotelaria. Ministra disciplinas do Eixo de

Indumentária do Curso de Licenciatura em Belas Artes da Universidade Federal Rural do Rio de Janeiro, Campus Seropédica/RJ.

$\S$ Doutora em Artes Visuais na Escola de Belas Artes da Universidade Federal do Rio de Janeiro. Docente do Curso Técnico Pós-médio de Produção de Moda da FAETEC.

* Email de correspondencia: karolikosa@hotmail.com 
mundo, de hierarquias de valores, de relações sociais, de visões acerca das identidades e das diferenças" (SOUSA, 2019, p.45).

Especificamente na cultura húngara, os bordados ocupam espaço significativo e estão presentes em diversos momentos, nos quais se enumeram variados tipos de técnica de ornamentação têxtil, entre eles, o bordado Kalocsai, originário da região da Kalocsa. Segundo o comitê do Patrimônio Cultural Imaterial da Hungria - ICH (2009), os motivos florais coloridos da pintura decorativa e do bordado de Kalocsa são amplamente conhecidos, costumam ser considerados um símbolo emblemático da arte folclórica húngara e representam o único elemento da cultura camponesa tradicional dessa região. $\mathrm{Na}$ contemporaneidade, as mulheres de Kalocsa que ainda desenham, pintam e bordam no estilo tradicional, são tidas como portadoras e perpetuadoras do patrimônio local.

Durante o século XX, no processo imigratório para o Brasil, junto com os bordados, os imigrantes húngaros trouxeram à técnica, as cores, as linhas, a paisagem e os elementos das naturezas retratadas, a reunião de mulheres, o afazer exclusivamente feminino, e o significado social do ato de bordar.

Nesse sentido, busca-se analisar a aplicação do bordado Kalocsai em um artigo do vestuário produzido em território brasileiro, por uma imigrante, e seus respectivos processos de produção técnica, simbólica e de ressignificação .

É importante ressaltar que, na arte popular Húngara, os ornamentos das vestimentas podem se diferenciar de acordo com o local, a ocasião, gênero e idade. Assim, os Kalocsai seguem um padrão estrutural e de cor que lhes permitem serem identificados. E, sendo o Brasil um país miscigenado, conhecer as características culturais dos países de origem de seus imigrantes, implica também em conhecer e estudar sobre a cultura brasileira.

\section{O bordado Kalocsai: da hungria ao brasil}

A cidade Kalocsa, localizada na Hungria (como identificado na Figura 1), pertence à região denominada Grande Planície do Sul, a cerca de 110 km de distância de Budapeste, capital do país. Foi um dos bispados fundados pelo primeiro Rei da Hungria, Estêvão I, era próspera até ser saqueada pelos turcos.

A cidade se reergue no século XIX como centro agrícola e de processamento de alimentos, por suas terras férteis graças à proximidade do rio Danúbio. Kalocsa é formada por aldeias que surgiram a partir das fazendas locais que produziam trigo para o mercado nacional. Assim, o povoado da cidade participou do crescimento

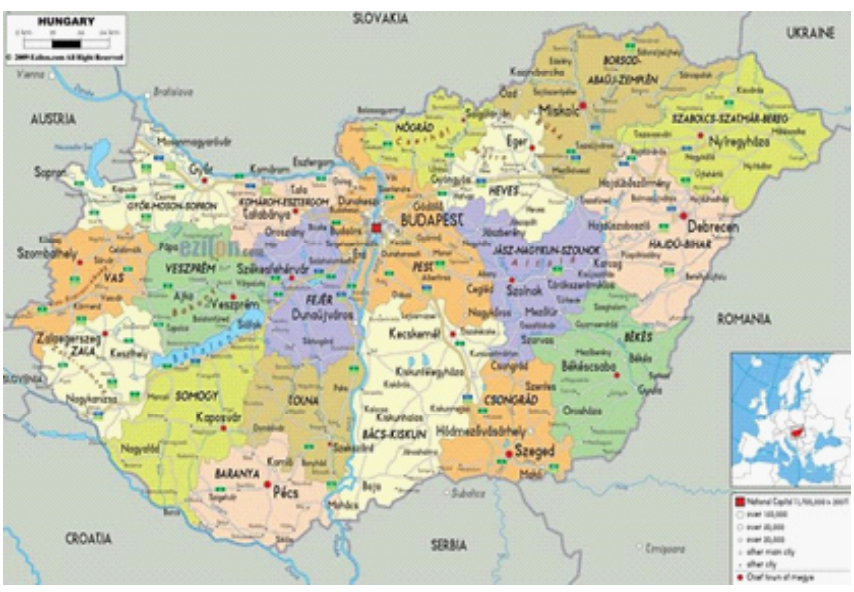

Figura 1. Mapa da Hungria e localização da cidade Kalocsa

Fonte: Maps Hungary

comercial do país, obtendo acesso aos tecidos de fábrica e sedas coloridas, incentivando a criação de adornos em peças de vestuário (HÉDER, 2007).

Os motivos Kalocsai foram inspirados no kékfestő - técnica de impressão ou estamparia de motivos florais brancos sobre tecido azul ou índigo em peças de decoração e vestuário, que era produzido na região Sárköz, próximo à Kalocsa. Então, nesta cidade:

[...] uma impressora de bordar foi montada para criar novos motivos, o que foi uma grande conquista para as senhoras burguesas. Foram elas que insistiram em ensinar as camponesas a bordar de acordo com a nova moda, para que o trabalho de agulha fosse de alta qualidade (HÉDER, 2007)

As mulheres camponesas não só bordavam para as senhoras burguesas, como também para elas mesmas, copiando os desenhos feitos na imprensa, tendo em vista o alto custo do serviço que estas, por sua vez, não poderiam arcar. Os desenhos sofreram mudanças de simplificação quanto à configuração, e entende-se que a partir destas mudanças o ponto cheio com fios brancos começou a preencher os rascunhos nos tecidos. Os padrões de estampas aplicavam-se como pinturas em diversos suportes, tais como paredes, móveis, louças e bordados sobre tecidos. Sobre isto, Milley (2018) discorre sobre suas lembranças em seu livro biográfico e recorda:

[...] os móveis do quarto de meus pais estão fotografados em minha memória. Eram azuis com um detalhe muito particular. Todas as peças tinham uma barra pintada com motivos de arte popular húngara. Esses desenhos eram os mesmos que se repetem em bordados, louça e peças de cerâmica (MILLEY, 2018, p.20).

Desde o seu aparecimento no século XIX, a aparência do bordado foi sendo modificada de forma gradual, com a adição de cores. "Primeiro, o preto substituiu as flores brancas, então a combinação de vermelho e azul apareceu" (HÉDER, 2007). A partir do final da década de 1920, período entre a Primeira e a Segunda Guerra Mundiais, os bordados Kalocsai 
assumem sua forma atual, coloridos com vermelho, azul, amarelo, verde, rosa, roxo e suas variações sempre vibrantes, em fundo branco. Apesar de ser uma tradição cultural relativamente recente, sua rápida ascensão explica-se, de acordo com o etnógrafo Klára Csilléry , pelo desejo da sociedade rural de renovar peças de vestuário, elevar sua beleza e assim encantar quem as vir, como também acrescentar valor às vestimentas (HÉDER, 2007).

Por fim, a maneira peculiar de criar os desenhos e combinar as cores nesta cidade originou o nome deste tipo de bordado. A Língua Húngara é aglutinante, onde o sufixo [-i] indica uma cidade. Sendo assim, a palavra "Kalocsai" significa "de Kalocsa" [Kalacsa].

No Brasil, a presença da cultura húngara se deve ao processo imigratório, dividido em quatro principais etapas, iniciadas em 1890. Entretanto, os primeiros registros de personalidades húngaras em território brasileiro datam por volta de 1820 , à maioria por motivos de trabalho.

A primeira etapa é marcada pela entrada significativa de grupos húngaros atraídos pelas políticas de imigração brasileiras, alocando-se na região sul do país e no interior de São Paulo. A segunda se deu após o fim da Primeira Guerra Mundial (1914 - 1918), onde foi assinado o Tratado de Trianon, que provocou a insatisfação nos húngaros que perderam sua nacionalidade repentinamente por efeito do desmembramento territorial da Hungria, promovendo a imigração. A Segunda Guerra Mundial (1939 - 1945) motivou a terceira etapa de chegada de grupos e famílias ao Brasil, registrado pela Prefeitura de Jaraguá do Sul RS, a partir de 1945:

[...] Eram na maioria militares, oficiais, profissionais liberais. Fugiam da guerra ou da ocupação militar soviética e do regime comunista imposto pela União Soviética. Aprenderam a língua portuguesa, revalidaram seus diplomas, abriram firmas, pequenas fábricas, consultórios e começaram assim a sua nova vida (ARENDT, 2019).

Em outubro de 1956 inicia-se uma revolução popular contra as tropas da União Soviética - Revolução Húngara. A população pedia uma reforma econômica e política, alteração no sistema de importação e exportação, entre outras melhorias. Esta quarta e última grande etapa da imigração trouxe principalmente famílias de jovens com formação universitária ou técnica que se instalaram em maior parte na cidade de São Paulo.

\section{Perpetuando as tradicões húngaras no Brasil}

Com a finalidade de acolher imigrantes compatriotas e, de certa maneira, manter a memória e os costumes da cultura húngara, Helene Joó de Kokron fundou, em 1952, em São Paulo, a Liga das Senhoras Húngaras em conjunto com Dom Emilio Jordán então prior do mosteiro de São Geraldo (dos padres beneditinos húngaros). Entre as atividades, era ensinado às senhoras as técnicas de bordadura.

Assim, o ato de bordar e seu produto final exerciam papel econômico-cultural, onde a reprodução de peças bordadas mantinha as recordações da pátria, em concomitância, a venda destas peças gerava renda para suprir necessidades pontuais, tal como a manutenção do grupo de escoteiros húngaros e a subsistência das próprias famílias envolvidas.

Atualmente, existem grupos e eventos culturais mantidos por descentes húngaros que cumprem o papel de preservação cultural, entre eles: a Confraria Húngara do Rio de Janeiro; Grupo de Danças Folclóricas Húngaras Pántlika e as ações da Universidade de São Paulo.

A Confraria Húngara do Rio de Janeiro é constituída por um grupo de húngaros e descendentes que se associaram para o mesmo fim: perpetuar a cultura magyar. Suas atividades visam o fortalecimento e preservação dos valores, cultura e tradições húngaras. Desde novembro de 2015, a Confraria promove reuniões mensais cujas pautas abordavam a troca de experiências, estudo e prática do idioma e mais assuntos pertinentes à Hungria. Ademais, a Confraria sistematiza palestras sobre a cultura e língua, organiza caravanas a eventos com presença de húngaros a fim de prestigiá-los, e visitas aos pontos significativos da cidade, que fazem parte da trajetória e história da comunidade húngara no Brasil.

O Grupo de Danças Folclóricas Húngaras Pántlika, formado em 1968, por Ilona Kokron, tem como o objetivo de manter, divulgar e apresentar a cultura húngara através da dança para os imigrantes húngaros, seus descendentes e também para o povo brasileiro (ASSOCIAÇÃO HÚNGARA) . Seus integrantes são crianças e adultos, filhos e netos de imigrantes da colônia de São Paulo. Além da dança em trajes típicos, o grupo mantém um conjunto de tradições regionais, incluindo as de Kalocsa, e conta com um acervo de indumentária constituído por reproduções feitas no Brasil e peças autênticas confeccionadas na Hungria.

Por último, a Universidade de São Paulo mantém relações estreitas com a cultura Húngara, visto que as comunidades de húngaros e de descendentes concentram-se, em maioria, na cidade. Além dos cursos de difusão da língua e da cultura húngara (FFLCH, 2019) , a organização também promove eventos acadêmicos concernentes à Hungria, contando com a cooperação da comunidade húngara, da Embaixada da Hungria no Brasil, entre outros cooperadores. Dentre eles, a Conferência sobre a Presença Húngara no Brasil. 


\section{Método}

A presente pesquisa se deu a partir da análise de uma peça do vestuário decorativo, toalha de mesa, produzida por uma imigrante húngara, confeccionada no ano de 1972, no Rio de Janeiro. Artigos para o lar estão dentre as principais peças que recebem a aplicação dos bordados Kalocsai.

Buscando melhores condições econômicas e refugiando-se da Segunda Guerra Mundial, a imigrante húngara, seus pais e irmão escolheram o Brasil como sua nova pátria. Desembarcaram em Santos - SP, em 17 de maio de 1957, onde encontraram uma colônia de húngaros imigrantes. Era comum e de costume, húngaros casarem com pessoas da mesma nacionalidade, assim sendo, a imigrante casou-se também com um imigrante húngaro, em São Bernardo do Campo, São Paulo, onde morou por algum tempo, e após, mudou-se para o Rio de Janeiro.

Vindo para o Brasil, a imigrante trouxe somente objetos necessários, no entanto, trouxe muitas memórias de sua pátria. Costumes, cantigas, receitas de comidas típicas, a língua húngara e um fazer especialmente feminino: ornamentar com fios artigos de vestuário. Ainda na Hungria, as técnicas haviam sido ensinadas e aplicadas em peças de enxoval e traje folclórico típico por sua mãe, que também auxiliou na produção da toalha de mesa com os riscos dos desenhos, pontos utilizados, entre outras técnicas.

Os motivos Kalocsai bordados na toalha e seus ornamentos demandaram um período de aproximadamente três meses para serem finalizados, pois o trabalho de bordar era dividido com outros afazeres domésticos. Para análise foram considerados os seguintes aspectos: têxteis (tipo de tecido, linhas, dimensões, estado de conservação, possíveis variações de cores e texturas), técnicos (tipo de pontos, uso das cores, motivos, esquema de bordadura etc.) e simbólicos.

Além de teste de chama para detecção da composição do tecido e da linha, foram utilizados outros recursos metodológicos, como: medição da toalha com fita métrica, observação e descrição detalhada da peça; identificação de cores e tipos de pontos utilizados; reconhecimento da presença de ritmo, repetição e espelhamento no bordado; e comparação do exemplar com outros bordados (trajes folclóricos da região da Kalocsa). Também foi utilizada a pesquisa bibliográfica, no sentido de embasar e referendar a análise da toalha.

\section{Análise da peça}

\section{Formato}

A toalha de mesa (Figura 2) possui o tamanho $1,71 \mathrm{~cm}$ de comprimento por $88 \mathrm{~cm}$ de altura. Em suas extremidades, uma borda de crochê de $6 \mathrm{~cm}$ de altura rodeando e dando acabamento à peça. Seis desenhos compõem o bordado total: os quatro menores, um em cada um dos quatro cantos, medindo $28 \mathrm{~cm}$ de largura por $21 \mathrm{~cm}$ de altura; e dois maiores, localizados no centro inferior e superior entre os dois bordados menores, medindo $58 \mathrm{~cm}$ de largura por $15 \mathrm{~cm}$ de altura. Com base nestes dados, verificamos que a toalha de mesa possui tamanho mediano de formato retangular, conforme imagem a seguir (Figura 2).

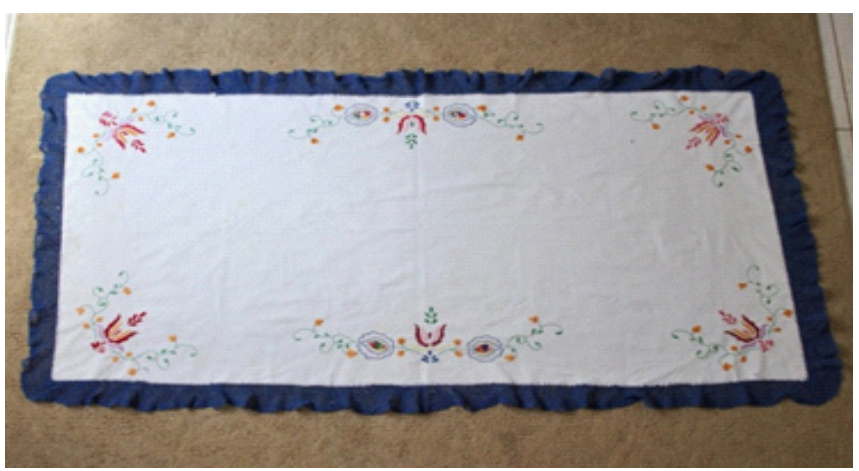

Figura 2. Toalha de mesa com motivos Kalocsai

Fonte: Arquivo pessoal - Foto: Bianca Aguiar, 2019.

\section{Composição têxtil}

O tecido utilizado na peça é o vaszón, tecido de origem húngara, cuja composição é a fibra natural vegetal algodão, na cor branca, provavelmente, alvejado. A linha utilizada para a feitura dos bordados é dupla retorcida $100 \%$ algodão, de toque macio e pigmentação levemente desbotada.

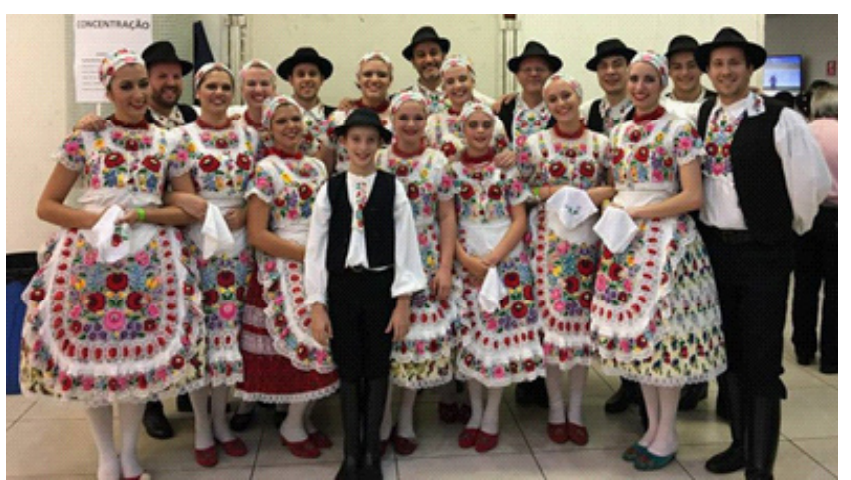

Figura 3. Integrantes do Grupo Pántlika com traje típico de Kalocsa

Fonte: Associação Húngara, 2019 
Conforme consta no acervo de indumentária da Associação $\mathrm{H}$, o vaszón é o tecido utilizado em outras peças decorativas e no traje folclórico típico de Kalocsa, constituído, por um conjunto de dez peças, ornamentadas com os bordados da mesma região, o Kalocsai, como mostra a Figura 3.

\section{Acabamento da toalha}

No sentido do urdimento do tecido, as bordas da toalha foram arrematadas com ponto zigue-zague em máquina de costura doméstica e, no sentido da trama, as bordas foram finalizadas com dobradura de bainha simples, a fim de evitar o esgarçamento da peça. Por fim, como acabamento estético foi adicionado uma borda de crochê com ponto corrente, na cor azul, onde se encontram alguns pontos desfeitos, como mostra a Figura 4.

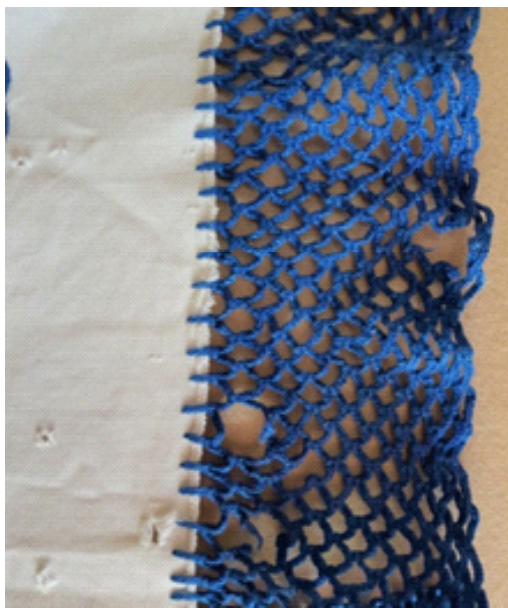

Figura 4. Detalhe da borda em crochê

Fonte: Arquivo pessoal - Foto: Karolina Kosa, 2019.

\section{Desgaste da toalha}

$\mathrm{Na}$ figura 4, nota-se a presença de avarias no tecido da toalha (furos) e esfacelos na renda de acabamento (crochê). Além desses, percebe-se a presença de manchas, como mostra o detalhe destacado na Figura 5.

Com o passar dos anos ocorreram avarias naturais, isto por que, tratando-se de um material têxtil de origem vegetal, sua deterioração é inevitável. Sobre esse fato, Viana e Neira (2010) discorrem:

[...] a deterioração é tanto maior quanto a presença de substâncias agressoras das fibras, que podem ter sido incorporadas durante o processo de fabricação dos têxteis, quando de seu uso (sujeitos às bactérias/fungos do suor, por exemplo) ou de sua guarda e exposição (luminosidade, umidade etc.). Assim, por mais que uma peça têxtil tenha sido cuidadosamente tratada, a sua própria configuração, principalmente quando se trata de materiais de origem orgânica, dará início a um processo de 'autoeliminação' (VIANA; NEIRA, 2010, p. 215).

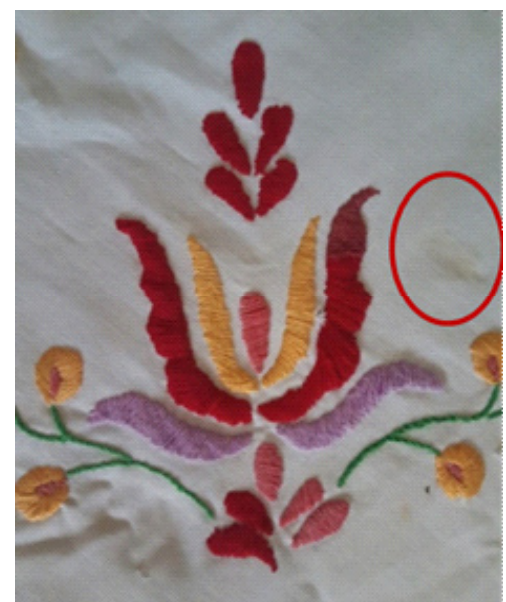

Figura 5. Detalhe do bordado da extremidade

Fonte: Arquivo pessoal - Foto: Karolina Kosa 2019 .

A função da toalha era proteger e enfeitar a mesa de refeições, por este motivo observam-se manchas de uso amareladas provenientes de respingos de alimentos, como também pequenos orifícios e rasgos decorrentes do desgaste a partir da lavagem e, conjuntamente, da ação do tempo. Ademais, no tecido encontram-se pequenos orifícios, enquanto na borda encontram-se pontos desfeitos ou rasgados, culminando na abertura de buracos na aplicação de crochê.

\section{Bordado: risco, motivos, simetria, pontos, acabamentos e cores}

Sobre a elaboração do bordado Kalocsai é de conhecimento público uma sequência de passos para sua execução. Em primeiro lugar, são escolhidos os motivos e realizado um esboço em papel do desenho a ser bordado. Logo após a escolha dos motivos, o desenho é riscado sobre o tecido com uma caneta ou simplesmente um lápis, para então dar início a bordadura.

A feitura do risco torna explícito o processo de criação do bordado. A disciplina surge como regra para um bom bordado: obedecer ao risco. Apesar de envolver disciplina, busca pela simetria e apurado senso estético, organizar o risco vai além por revelar que o processo de criação apenas se completa pelas várias combinações de pontos e temas, somadas à experiência com os materiais 
disponíveis (BRITO, 2010).

Em geral, os motivos bordados são inspirados em flores. É importante dizer que, as flores são a principal fonte de inspiração nos bordados Kalocsai. Além das flores, é comum a páprika ou pimentão, especiaria muito usada na culinária húngara e, por isso, um dos símbolos do país, sendo também amplamente representada nos bordados.

Um ponto de destaque sobre o bordado Kalocsai é a existência de um padrão que se repete nos riscos, a simetria e a configuração espelhada, ou seja, se dobrados ao meio, os desenhos são iguais em ambos os lados, tal como pode ser observado na Figura 2. Além dos desenhos invariavelmente simétricos, a toalha também apresenta tal característica entre o conjunto de bordados. Isso significa dizer que os bordados se repetem em ambos os lados da toalha retangular, como em um espelho.

Sobre o ponto utilizado para a realização do bordado na toalha, como mostra a Figura 5, tem-se o ponto manual "ponto cheio", que é classificado como ponto de encher. Nos bordados, os pontos de encher compõem áreas definidas por pontos de contorno ou caseado, e são dispostos em: carreiras regulares formando padrões geométricos e linhas retas; superfície texturizada por meio de pontos juntos; espaçados, deixando entrever o tecido sob o qual é aplicado ou espalhado ao acaso. Pontos menores se prestam a formar enchimento de pontos isolados do bordado, e, os pontos maiores, usados como realce (FUSSESP, 2018).

O "ponto cheio" é um grupo de pontos retos, próximos uns aos outros, com superfície em relevo, cujo avesso e direito da peça do bordado tem a mesma aparência. Nesse ponto, a agulha com linha é posicionada em um dos lados da figura a ser bordada, perfura o tecido e atravessa seu desenho, de onde se recomeça o processo, até o preenchimento total do desenho (FUSSESP, 2018), comum aos bordados húngaros, o ponto cheio é tido como padrão.

Sobre o arremate dos pontos do bordado presentes na toalha percebe-se a presença do acabamento húngaro. A maneira de iniciar e finalizar a bordadura húngara dispensa o tradicional nó, uma vez que este forma uma proeminência prejudicial à aparência estética final do trabalho. À vista disto, o bordado é iniciado com alguns pontos no centro do desenho e o arremate consiste em passar a linha ainda na agulha por entre o bordado, de maneira que fique acobertada e segura pelos fios firmemente costurados, cuidando para que não se solte.

Em uma entrevista ao jornal semanal on-line Terrebonne Parish Government Television, a especialista em bordados húngaros Ruby Petho relata sua vivência com o assunto e aponta as principais características que tornam o trabalho diferenciado:

No estilo de bordado húngaro, cada linha fica lado a lado da outra As linhas de bordadura húngara são mais grossas do que as linhas de bordadura de outros países. Também é sabido que nas costuras húngaras, o lado interior das peças são tão macios e perfeitos quanto o exterior. As peças são costuradas com muitos pontos, mas eles são fechados de forma simples, sem muitas ferramentas emelhor, sem nós. Esse é o principal diferencial do bordado húngaro (PETHO, 2014).

Sobre as cores empregadas no bordado da toalha, como mostram as Figuras 2 e 5 tem-se o azul, o vermelho, o rosa de diferentes tonalidades, o amarelo, o lilás e o verde, buscando uma harmonização entre o bordado e o acabamento em crochê nas laterais, a bordadeira optou pelo uso do azul para o crochê.

Como é comum no bordado Kalocsai, a inspiração das cores segue a composição natural das flores. Geralmente, as pétalas da mesma flor recebem cores diferentes em tons de rosas, vermelhos e laranjas, contrastando com os tons de verdes dos ramos e folhas.

O bordado é colorido, tal como passou a ser prática a partir do início do século XX. No traje folclórico típico de Kalocsa (Figura 3), os ornamentos podem variar em alguns aspectos como cores - mais vivas para as moças jovens e opacas para as mais maduras; local de aplicação, acréscimo de babados e o emprego da renda Richelieu .

Pela análise da toalha, observa-se, ainda, uma variação de tonalidade de cores tanto entre as flores em geral quanto na composição da mesma flor, que evidencia o proveito de outras linhas na falta da mesma para o término do trabalho, vide Figura 5:

A Figura 5 mostra também as diferenças tonais na ponta da pétala vermelha à direita, como também em três detalhes em formato de gotas, logo abaixo da flor. Estas variações se explicam pela mudança da linha empregada no bordado.

Assim, considera-se que o bordado Kalocsai realizado no Brasil apresenta aspectos têxteis e técnicos semelhantes aos produzidos em seu país de origem. Por outro lado, como herança cultural, o conjunto de dimensões sociais e simbólicas fez e faz com que os motivos Kalocsai, apresentados na toalha, sejam ressignificados fora de seu país de origem, pois como produto da cultura húngara produzida em território brasileiro, seu propósito vai além da utilidade doméstica, tornando-se a memória materializada de seu país e de sua cultura natal. Assim, como no caso da toalha analisada, o bordado assume a função de elo entre a cultura vivenciada (brasileira) com a cultura de origem (húngara).

O fator geracional também pode ser destacado na confecção da peça e do bordado, uma vez que a mãe da autora a auxiliou em sua confecção, propiciando que a herança cultural de um povo seja preservada, mesmo que com algumas adaptações que são próprias da fluidez dos sistemas culturais.

Conforme Brito (2010), quando se aproxima da prática do bordado é comum ouvir que a arte de bordar é uma herança, passada de mãe para filha, pois é de uma 
geração para a outra que se aprende: o quê e como fazer, o que ensinar, quando ensinar, como ensinar, o que não ensinar e os segredos a serem mantidos.

Assim, como os demais processos de ensino do artesanato, o bordado é baseado na transmissão oral e na imitação. Aprende-se a bordar, observando o trabalho de outra pessoa, sendo comum, portanto, a aprendiz prestar auxílio à bordadeira em diversas tarefas que, muitas vezes, transcendem às que são ligadas ao bordado. $\mathrm{Ou}$ seja, o ensino e aprendizado do bordado apresenta mais do que a transmissão de uma técnica, uma vez que traz consigo concepções sobre o que é ser boa bordadeira. $\mathrm{E}$, ao mesmo tempo, apontam para uma preocupação corrente, na qual o bordado é uma prática em extinção (BRITO, 2010).

No caso da peça analisada, a realização do bordado, não tinha cunho econômico, de geração de renda, mas de uso particular e afetivo. A ressignificação do bordado no caso da peça analisada ultrapassa os limites de suas funções materiais, funcionais e decorativas, pois como o ato de bordar, representa o elo entre mãe e filha e da imigrante com sua origem. Como parte da memória familiar e cultural, esse bem material foi preservado pela família, fazendo parte do inventário afetivo da família Kosa.

\section{Considerações finais}

A chegada de imigrantes húngaros no Brasil propiciou a entrada de novas experiências sociais e artefatos dessa cultura. Estas concepções são mantidas por meio de iniciativas que evidenciam a importância dos bordados em peças de vestuário enquanto importante aspecto da cultura húngara.

Pela análise da toalha de mesa foi possível observar a presença de elementos têxteis e técnicos que tornam possível sua identificação como um exemplar do Kalocsai, tais como: a composição do tecido de base, o uso de cores, o ponto cheio, arremate sem o uso de nós, o cuidado para não haver diferença entre o anverso e o verso da peça, até a escolha dos desenhos e seus significados. Constatou-se, no entanto, que o bordado Kalocsai foi ressignificado, tendo em vista o conjunto de dimensões afetivas - memórias e lembranças - que evoca.

Destaca-se que, com a análise da peça, não se pretende estender suas conclusões para uma conjuntura do bordado Kalocsai no Brasil, embora haja pretensão de se avançar sobre a temática em pesquisas futuras, que agrupem um número maior de peças, bem como análise dos trajes típicos e entrevistas com executores do bordado no Brasil.

Ressalta-se, ainda, que são escassas as fontes de informações no que tange esse tipo de bordadura e a sua trajetória no Brasil. Portanto, reitera-se a importância de estudos que caminhem nesse sentido.

\section{Notas}

1. O bordado, a pintura decorativa, a roupas tradicionais e a dança folclórica da Kalocsa passaram a ser reconhecidos como Elementos do Inventário Nacional do Patrimônio Cultural Imaterial da Hungria, em 2012 (UNESCO, 2013).

2. A raiz do termo ressignificar implica em dar um outro sentido, uma nova significação. Ou seja, ressignificar está no campo do simbólico e não é o mesmo que trazer algo para o campo representacional pela primeira vez, mas refere-se a dar um novo sentido a algo que já estava lá. A medida em que tece novas relações de sentido, o sujeito abre caminho para novas ligações possíveis, permitindo também uma ampliação do trabalho de "puxar" elementos do real para dentro do campo do simbólico (JOHN, 2006).

3. A região de Sárköz, na Hungria, estende-se desde o Transdanubia Szekszárd até Bátaszék. E limitado pelo Danúbio do leste (HEDER, 2007).

4. Klára K. Csillery (Pétern Király). Etnógrafo húngaro, museólogo. Nasceu em Budapeste, 30 de agosto de 1923. Faleceu em Budapeste, 25 de junho de 2002 (HÉDER, 2007).

5.Helene Joó de Kokron, Húngara, mãe de Ilona Maria Kokron. Chegou ao Brasil em março de 1951 (ASSOCIAÇÃO HÚNGARA, 2019).

6. Liga das Senhoras Húngaras - Associação filantrópica que promove reuniões mensais, almoços, jantares, desfiles, aniversários coletivos, passeios culturais, concertos etc. Colabora com as outras entidades e pessoas, ajudando as que necessitam de apoio (ASSOCIAÇÃO HÚNGARA, 2019).

7. Grupo de Escoteiros Szondi György foi criado em 1949. Através dos acampamentos e excursões desenvolvem-se habilidades, a destreza e a segurança dos jovens e, sendo estas atividades em húngaro, fortalecem-se o conhecimento da língua e da cultura húngara (ASSOCIAÇÃO HÚNGARA, 2019)

8. Magyar: termo que significa "húngaro". Pode ser usado para referenciar tanto habitantes como cidadãos da República da Hungria (LUCENA, 2008).

9. Grupo de danças Folclóricas Húngaras. Associação Húngara. Disponível em: $<$ http://www.ahungara.org.br/grupos/pantlika $>$. Acesso em 20 de fevereiro de 2019

10. Curso de Língua Húngara da Universidade de São Paulo. Disponível em: $<$ http://letrasorientais.fflch.usp.br/hungaro $>$. Acesso em 20 de fevereiro de 2019 .

11. Conferência Sobre a Presença Húngara no Brasil. Disponível em: $<$ http:// hungarosnobrasil.000webhostapp.com/iv-conferencia-sobre-a-presencahungara-no-brasil/>. Acesso em 20 de fevereiro de 2019.

12. O nome da imigrante foi suprimido pela impossibilidade de autorização para a publicação do mesmo no artigo.

13. Vídeo Hungarian Art in Hungarian Settlement. Produção: Louisiana Hometown. 2014. Disponível em: $<$ https://www.youtube.com/watch?v=HIs FeGdJvFs\&feature=youtu.be $>$. Acesso: 12 out. 2019

14. Richelieu é um tipo de bordado de origem francesa, que pode ser feito a mão ou na máquina de costura. É composto por um conjunto de pontos (cheio, aberto e barrete), cujos desenhos são feitos a base de arabescos e referências florais. Sua feitura inclui o picote no tecido, tornando-o vazado com aspecto de renda (BRITO, 2010).

\section{Referências}

ARENDT, Ignácio. Etnias de Jaraguá do Sul - Hungria. Prefeitura de Jaraguá do Sul. Disponível em: http://www.jaraguadosul.sc.gov.br/etnias-de-jaraguado-sul-hungara. Acesso em: 14 mar. 2019.

ASSOCIAÇÃO HÚNGARA. Disponível em: http://www.ahungara.org.br/. Acesso em 14 mar. 2019

BRITO, Thaís F. S. Bordados e bordadeiras: um estudo etnográfico sobre a produção artesanal de bordados em Caicó/RN. Tese (doutorado) - 
Faculdade de Filosofia, Letras e Ciências Humanas, Universidade de São Paulo. São Paulo/SP, 2010. Disponível em: http://www.teses.usp.br/index. php?option $=$ com jumi\&fileid $=17 \&$ Itemid $=160 \& l a$

ng=pt-br\&id=97A5B77D11E9. Acesso em: 20 jan. 2020.

FUSSESP - FUNDO SOCIAL DE SÃO PAULO. Bordado de Linha. Escola de Qualificação Profissional de Moda. Fundo Social de São Paulo. Disponível em: http://www.fussesp.sp.gov.br/wp-content/uploads/2018/10/bordado-emlinha-2018-corrigida.pdf. Acesso em: 20 jan. 2020.

HÉDER, Enikö. El bordado de Kalocsa ayer y hoy - bajo las ágiles manos de las bordadoras y en los escaparates de Budapest. LHO, 2007. Disponível $\mathrm{em}$ : http://www.lho.es/index.php?pagetype=literary_corners\&id=1963\#self. Acesso em: 12 mar. 2019.

JOHN, Daniele. A ressignificação da história de vida: temporalidade e narrativa no percurso da análise. Tese (Doutorado) - Pontifícia Universidade Católica de São Paulo, 2006.

KLÁRA, K. Csillery. Disponível em: http://members.iif.hu/ibisz/hazai/lexi/ csilleri.html. Acesso em: 13 mar. 2019.

LUCENA, Simone Espin de Oliveira. Igreja cristã reformada do Brasil: identidade étnica e religião "um estudo de caso". Dissertação (Mestrado) Universidade Presbiteriana Mackenzie, São Paulo/SP, 2008. Disponível em: http://tede.mackenzie.br/jspui/handle/tede/2517. Acesso em: 13 mar. 2019.

MAPS HUNGARY. Disponível em:<https://pt.maps-hungary.com/hungriamapa>. Acesso em: 11 mai. 2020.

MILLEY, Agnes. Da Hungria ao Brasil: memórias que transbordam. Rio de Janeiro: Letra Capital, 2018.

ORGANIZAÇÃO DAS NAÇÕES UNIDAS PARA A EDUCAÇÃO, A CIÊNCIA E A CULTURA - UNESCO. Hungria: Relatório Periódico 20062012, publicação 2013 Disponível em: http://szellemikulturalisorokseg.hu/ doks/unesco_orszagjelentes_angol.pdf. Acesso em: 08 mai. 2020.

PATRIMÔNIO CULTURAL IMATERIAL DA HUNGRIA - ICH. Comitê do Patrimônio Cultural Imaterial da Comissão Nacional Húngara. Vivendo a herança tradicional no espaço cultural de kalocsa: bordado, pintura ornamental, trajes tradicionais e dança folclórica (2009). Disponível em: http://szellemikulturalisorokseg.hu/index0_en.php?name=en_0_kalocsa. Acesso em: 08 mai. 2020.

PETHO, Ruby. Hungarian Art in Hungarian Settlement. Louisiana Hometown, 2014. Disponível em:<https://www.youtube.com/watch?v=HIs FeGdJvFs\&feature=youtu.be $>$. Acesso em: 20 nov. 2018.

SIMIONI, Ana Paula. Bordado e transgressão: questões de gênero na arte de Rosana Paulino e Rosana Palazyan. Revista Proa, n. 02, v.01, p. 1-20, 2010.

SILVA, Paulo F. T. Lemos. Bordados tradicionais portugueses. Dissertação (Mestrado em Design e Marketing) - Departamento de Engenharia Têxtil, Universidade do Minho. 2006. Disponível em: http://repositorium.sdum. uminho.pt/handle/1822/6723>. Acesso em: 08 mai. 2020

SOUSA, Juliana Padilha. Tramas invisíveis: bordado e a memória do feminino no processo criativo. Dissertação (Mestrado) - Universidade Federal do Pará, Instituto de Ciências das Artes, Programa de Pós-Graduação em Artes, Belém, 2019. Disponível em: http://repositorio.ufpa.br/jspui/ bitstream/2011/11443/7/Dissertacao_TramasInvisiveisBordado.pdf. Acesso em 08 mai. 2020.

VIANA, Fausto e NEIRA, Luz García. Princípios Gerais de Conservação Têxtil. Revista CPC, São Paulo, n. 10, p. 206-233, maio/out 2010 